\title{
An Unusual Myeloma Case with Normal Erythrocyte Sedimentation Rate and Serum Immunoglobulins
}

\author{
Edip Erkus*, Gulali Aktas, Mehmet Zahid Kocak, Tuba T Duman, Burcin M Atak and Haluk Savli \\ Department of Internal Medicine, Abant Izzet Baysal University Hospital, Bolu, Turkey
}

*Corresponding author: Edip Erkus, Department of Internal Medicine, Abant Izzet Baysal University Hospital, Gokoy, 14280, Bolu, Turkey, Tel: +903742534656, Fax: +903742534615; E-mail: dr.ediperkus@gmail.com

Received Date: April 04, 2018; Accepted Date: April 17, 2018; Published Date: April 24, 2018

\begin{abstract}
Multiple Myeloma (MM) is a disease characterized by the increase of plasma cells in bone marrow or in other tissues and increased production of abnormal immunoglobulin (Ig) or Ig parts. In this report, we aimed to present a case of myeloma whom showed in our clinic with complaints of diarrhea, vomiting, fatigue and difficulty in walking. A 68year-old male patient presented with diarrhea, fatigue, nausea, vomiting, and loss of appetite. He had splenomegaly in physical examination. Laboratory test revealed erythrocyte sedimentation rate: $4 \mathrm{~mm} / \mathrm{h}$ and corrected calcium: 11.1 $\mathrm{mg} / \mathrm{dl}$. In conclusion, despite it is rare, multiple myeloma case may present with normal erythrocyte sedimentation rate and serum immunoglobulin levels. Anemia, bone lesions and hypercalcemia in an elderly may prompt diagnostic effort for multiple myeloma.
\end{abstract}

Keywords: Multiple myeloma; Erythrocyte sedimentation rate; Hypercalcemia

\section{Introduction}

Multiple Myeloma (MM) is a disease characterized by the increase of plasma cells in bone marrow or in other tissues and increased production of abnormal immunoglobulin (Ig) or Ig parts. The production of monoclonal Ig or Ig light chain is the main feature of the disease. The most commonly produced monoclonal protein is $\operatorname{IgG}$ or IgA. Less frequently immunoglobulin light chain or very rarely other types of Ig are produced. The median age of the patients is 65 and only $3 \%$ are under 40 years of age. Patients have a 5 -year survival rate of $25 \%$ and a 10 -year survival rate of around $5 \%$.

The etiology of the disease is not fully understood. It accounts for $1 \%$ of cancer-related deaths in Western countries [1,2]. It accounts for $1-2 \%$ of all malignancies and $10 \%$ of hematological malignancies. The incidence is four per 100000 populations. In recent years, the frequency has increased a bit. This increase depends on the longevity of people's lives and the frequent use of diagnostic tests [1].

In this report, we aimed to present a case of myeloma with showed in our clinic with complaints of diarrhea, vomiting, fatigue and difficulty in walking.

Citation: Erkis E. An Unusual Myeloma Case with Normal Erythrocyte Sedimentation Rate and Serum Immunoglobulins. J Clin Cases Rep 2018: 1(1):39-42. DOI: https://doi.org/10.46619/joccr.2018.1-1009 
www.tridhascholars.org | April-2018

\section{Case Report}

A 68-year-old male patient presented with diarrhea, fatigue, nausea, vomiting, and loss of appetite. He complained of difficulty in walking since he had knee arthroplasty operation 1 month ago. He diagnosed with Candida esophagitis in upper endoscopy 2 months ago. He has been treated for type 2 DM for 1 o years. His medications include lansoprazole $30 \mathrm{mg}$ daily, and insulin glargine 10 IU once daily.

His physical examination findings were as follows: Systolic and diastolic blood pressure was $100 \mathrm{mmHg}$ and $70 \mathrm{mmHg}$, respiratory rate was 16 per minute, heart beat was 96 per minute. Rest of the entire physical examination findings were normal except coarse respiratory sounds in basal of left hemi-thorax and bilateral pretibial edema $(+/+)$.

Laboratory findings of blood analysis include Potassium: $2.5 \mathrm{mmol} / \mathrm{l}$ (reference range: $3.5-5.5 \mathrm{mmol} / \mathrm{l}$ ), albumin: $2.6 \mathrm{~g} / \mathrm{dl}$ (reference range: 3.4-4.8 g/dl) CRP: $7.6 \mathrm{mg} / \mathrm{dL}$ (reference range: 0-5 mg/dL), cortisol: $13 \mu \mathrm{g} / \mathrm{dL}$ (reference range: $2.9-17.3$ $\mu \mathrm{g} / \mathrm{dL}$ ), parathyroid hormone: $9.7 \mathrm{pg} / \mathrm{ml}$ (reference range: $15-68.3 \mathrm{pg} / \mathrm{ml}$ ), glomerular filtration rate: $84 \mathrm{ml} / \mathrm{min} / 1.73 \mathrm{~m}{ }^{2}$, AST: 38 U/l (reference range: 5-34 U/l), ALT: 20 U/l (reference range: 0-55 U/l), adrenocorticotropic hormone: 5.21 pg/ml (reference range: 0-46 pg/ml), troponin: $1880 \mathrm{pg} / \mathrm{ml}(\mathrm{rd} \mathrm{0-26} \mathrm{pg/ml),} \mathrm{erythrocyte} \mathrm{sedimentation} \mathrm{rate:} 4 \mathrm{~mm} / \mathrm{h}$ (reference range: 0-20 $\mathrm{mm} / \mathrm{h}$ ), corrected calcium: $11.1 \mathrm{mg} / \mathrm{dl}$ (reference range: $8.8-10 \mathrm{mg} / \mathrm{dl}$ ), glucose: $110 \mathrm{mg} / \mathrm{dl}$ (reference range: $75-100 \mathrm{mg} / \mathrm{dl}$ ), vitamin B12: $550 \mathrm{pg}$. A 24 hours urine analysis revealed protein: $5420 \mathrm{mg} /$ day (reference range: 0-300 mg/day), microalbumin: $5105 \mathrm{mg} /$ day (reference range: $0-30 \mathrm{mg} /$ day).

Hemogram test results showed a white blood cell count of $6630 / \mathrm{mm}^{3}$, hemoglobin $9.4 \mathrm{~g} / \mathrm{dl}$, platelet count $209000 / \mathrm{mm}^{3}$.

Chest radiogram revealed a hypodense lesion in the right lung periphery. The patient was diagnosed with acute coronary syndrome due to clinical findings and increased troponin levels. Coronary angiography revealed narrowing in coronary arteries that just required medical treatment.

In thoracic and abdominal CT, soft tissue masses (metastasis) causing destruction of the bones in the right fifth costae and sternum, multiple lytic lesions in the thoracic vertebrae and left clavicle, splenomegaly, multiple lytic lesions in the left iliac wing and lumbar vertebrae lesions (metastasis) and nonspecific nodules in the lung were detected. Atypical cells were not detected in the peripheral blood smear. Upper and lower gastrointestinal endoscopy were normal. Anti-gliadin IgA and IgG, anti-endomisium $\operatorname{IgA}$ and $\operatorname{IgG}$ and tissue transglutaminase $\operatorname{Ig}$ A tests were negative for Celiac disease.

In serum protein electrophoresis, increase in a-1 and a-2 bands by $7.1 \%$ (reference range: $2.9 \%-4.9 \%$ ) and 17.8 (reference range: $7.1 \%-11.8 \%$ ) along with a decrease in gamma band by $8.8 \%$ (reference range: $11.1 \%-18.8 \%$ ) detected.

Of serum immunoglobulins, IgM was $<25 \mathrm{mg} / \mathrm{dL}$ (reference range: $22-240 \mathrm{mg} / \mathrm{dL}$ ), IgA was <85 mg/dL (reference range: 101 $645 \mathrm{mg} / \mathrm{dL}$ ) IgG was <320 mg/dL (reference range: $540-1822 \mathrm{mg} / \mathrm{dL}$ ).

Brain MR imaging of patients revealed common metastatic lesions in calvarium, clivus, and cervical vertebrae along with cerebral atrophy. A transthoracic biopsy was performed to the metastatic lesion destroying the right fifth costae. Plasma cells were detected in histopathologic examination of the biopsy material which showed positive staining for CD38, and kappa and negative staining for lambda, pancytokeratin and CD68. 
www.tridhascholars.org | April-2018

Blood and urine cultures obtained since fever developed. Klebsiella pneumonia was found in the urine culture, but blood cultures were negative. Ceftriaxone 1 gr twice added to daily treatment of the patient. His symptoms relieved by this regimen.

The patient was referred to the Hematology department with a diagnosis of plasma cell myeloma. The chemotherapy treatment of the patient continues in the hematology unit.

\section{Discussion}

We presented here an unusual multiple myeloma case characterized with increased production of Kappa light chain.

Multiple myeloma is a disease of elderly. Median age subjects with multiple myeloma is 69 years and most of the patients are men [3]. Present multiple myeloma case was a 68 year old man which was consisted with literature.

Multiple myeloma is usually characterized with anemia (mostly anemia of chronic disease), hypercalcemia, lytic bone lesions, kidney disease, however, it can be diagnosed in asymptomatic stage, too [4]. In present case, patient had hypercalcemia, anemia of chronic disease, bone lesions and stage 2 chronic kidney disease.

Splenomegaly and lymphadenopathy are rare findings in multiple myeloma. On the other hand, increased serum immunoglobulins, and elevated erythrocyte sedimentation rate are usually frequent features of the disease. In contrast to literature knowledge, present case had low serum immunoglobulin and normal erythrocyte sedimentation rate along with splenomegaly.

Direct radiographs may show lytic and metastatic bone lesions in subjects with multiple myeloma. However, PET CT or magnetic resonance imaging (MRI) studies may be required if plain films fail to show any bone lesions [5]. The patient presented had lytic bone lesions in direct graphics in sternum, costae and vertebrae.

Infection is a common problem during the course of multiple myeloma due to hypogammaglobulinemia. A study in literature higher risk of infectious complications in multiple myeloma subjects [6]. Urinary tract infection developed in present case responded well to ceftriaxone therapy.

In conclusion, despite it is rare, multiple myeloma case may present with normal erythrocyte sedimentation rate and serum immunoglobulin levels. Anemia, bone lesions and hypercalcemia in an elderly may prompt diagnostic effort for multiple myeloma.

\section{References}

1. Coskun HS, Er O and Ilhan O (2001) Multiple myeloma: Current approach. Erciyes Medical Journal 23: 83-90.

2. Bataille R and Harousseau JL (1997) Multiple myeloma. The New England Journal of Medicine. 336(23): 16571664.

3. http://seer.cancer.gov/statfacts/html/mulmy.html.

4. Röllig C, Knop S, Bornhäuser M (2015) Multiple myeloma. Lancet 385(9983): 2197-2208.

5. Dimopoulos M, Terpos E, Comenzo RL, et al. (2009) International myeloma working group consensus statement and guidelines regarding the current role of imaging techniques in the diagnosis and monitoring of multiple 
www.tridhascholars.org | April-2018

Myeloma. Leukemia 23(9): 1545-1556.

6. Sørrig R, Klausen TW, Salomo M, et al. (2018) Risk factors for blood stream infections in Multiple myeloma: A population-based study of 1154 patients in Denmark. European Journal of Hematology. 